\title{
A INTERNET: INSTRUMENTO DE SOCIALIZAÇÃO E FOMENTO DA AUTONOMIA DECISÓRIA?
}

\author{
Daniela Zilio* \\ Riva Sobrado de Freitas*
}

\begin{abstract}
RESUMO
O presente artigo objetiva averiguar se a internet pode servir como meio de socialização, através do fomento à autonomia decisória dos indivíduos. Realizou-se uma pesquisa bibliográfica exploratório-explicativa, qualitativa, utilizando-se o método dedutivo. Como resultado e contribuição, tem-se que, muito embora em determinadas e específicas circunstâncias, de fato, a internet possa favorecer o isolamento social, desde que usada de acordo com os ditames preconizados pelo bom senso, com parcimônia e respeitando os limites da legalidade, pode favorecer a socialização dos indivíduos, e fomentar o desenvolvimento de sua autonomia decisória.

Palavras-chave: Internet; Autonomia decisória; Socialização; Isolamento social; Liberdade de expressão.
\end{abstract}

\section{THE INTERNET: INSTRUMENT OF SOCIALIZATION AND PROMOTION OF THE DECISIONAL AUTONOMY?}

\begin{abstract}
This article aims to inquire if the internet can serve as mean of socialization, through the promotion of the individuals' decisional autonomy. It was done a bibliographical exploratoryexplanatory search, qualitative, using the deductive method. As a search result and contribution, it has that although in certain and specific situations, surely, the internet can favor the social isolation, since used according with the dictates recommended by common sense, with parsimony and respecting the limits of legality, can favor the socialization of individuals, and promote the improvement of their decisional autonomy.

Keywords: Internet; Decisional autonomy; Socialization; Social isolation; Freedom of speech.
\end{abstract}

\section{INTRODUÇÃO}

\footnotetext{
* Doutoranda e Mestra em Direito pelo Programa de Pós-graduação em Direito da Universidade do Oeste de Santa Catarina - Unoesc. Especialista em Direito Civil e Direito Processual Civil e especialista no Novo Sistema Processual Civil Brasileiro pela Universidade do Oeste de Santa Catarina - Unoesc. Professora do Curso de Direito da Universidade do Oeste de Santa Catarina - Unoesc, Campus de São Miguel do Oeste e Unidade de Pinhalzinho. Membro do Grupo de Estudos e Pesquisa "Interculturalidade, Identidade de Gênero e Personalidade", vinculado ao Programa de Pós-graduação em Direito da Universidade do Oeste de Santa Catarina. Advogada. Chapecó-SC. E-mail: danielazilio@yahoo.com.br.

* Pós-doutora em Direito pela Universidade de Coimbra; Doutora e Mestre em Direito pela Pontifícia Universidade Católica de São Paulo; Professora e pesquisadora do Programa de Pós-Graduação em Direito da Universidade do Oeste de Santa Catarina (UNOESC - Chapecó/SC). Professora Adjunta Aposentada de Direitos Humanos da Universidade Estadual Paulista “Júlio de Mesquita Filho" (UNESP) - Campus Franca (São Paulo). Chapecó-SC. E-mail: rivafreit@gmail.com.
} 
O estudo em comento tem como tema central a análise da internet, verificando-se se essa ferramenta pode servir de instrumento de fomento à autonomia decisória, e como meio de socialização, a despeito de tanto falar-se sobre o isolamento social que pode ocorrer devido ao seu uso.

A justificativa da pauta centra-se em primeiro plano na atualidade do tema. A internet é, de fato, uma ferramenta imprescindível nos dias hodiernos, mas, as consequências (positivas ou negativas) do seu uso ainda geram polêmicas. De seu turno, a autonomia decisória, ponderada a partir do indivíduo socializado, é um assunto inovador e que merece atenção. A junção de ambos os temas leva a uma reflexão extremamente importante e, portanto, necessária.

O problema do estudo encontra-se no seguinte questionamento: A internet pode servir de instrumento de socialização e como forma de fomento à autonomia decisória?

Objetiva-se, de forma geral, investigar-se a possibilidade de que a internet sirva de meio não de isolamento, mas de sociabilidade, através do desenvolvimento da autonomia decisória, pautada no direito à informação. De forma específica, estudar a autonomia; o ponto de vista segundo o qual a internet pode levar ao isolamento social; e, após, fazer o contraponto, investigando a internet enquanto meio de socialização e concretização da autonomia. Assim, tem-se como foco ponderar, no presente trabalho, a relação existente entre a internet e a sociabilidade, e ao mesmo tempo, aquela como ferramenta de apoio à construção da autonomia de cada indivíduo, na medida em que potencializa o seu poder de decidibilidade. Também, como corolário, o direito à liberdade de expressão merece ser ponderado e averiguado, sempre com parcimônia, eis que se sabe que, em hipótese alguma a internet é, ou deve ser, uma "terra de ninguém", sem punições aos excessos cometidos.

Para tanto, o estudo será sistematizado de modo que, em um primeiro momento será realizada a explicitação do conceito de autonomia, de liberdade, e de liberdade de expressão, adentrando-se especificamente em uma nova forma de abordagem do tema denominado autonomia, consubstanciada no que se define por autonomia decisória. Em um segundo momento, verificar-se-á a internet enquanto ferramenta que leva ao isolamento social. Por fim, far-se-á o cotejo, ponderando-se a internet enquanto forma de socialização e meio de incentivo ao desenvolvimento da autonomia.

Ressalta-se como principal referencial teórico a ser utilizado para chegar-se à resposta do questionamento levantado, o ideário defendido pelo sociólogo Manuel Castells. 
Por fim, em relação ao aspecto metodológico, a pesquisa alicerça-se em procedimentos técnicos, racionais e sistemáticos, com a finalidade de embasamento científico, proporcionando fundamentos lógicos à investigação. Trata-se, enfim, de pesquisa de coleta bibliográfica exploratório-explicativa, qualitativa, em que é utilizado o método dedutivo, e em que se tem o propósito de explorar e descrever o tema em apreço, revelando-se as possíveis soluções para o embate que se apresenta, sem, entretanto, esgotar-se a temática.

\section{A AUTONOMIA, A LIBERDADE E A LIBERDADE DE EXPRESSÃo}

Em um primeiro momento, necessário mencionar-se que, ponderada sob os pontos de vista dos mais críticos, a autonomia não é um conceito de único significado, nem tem a pretensão de ser, nem na filosofia, nem no direito e, quiçá, na opinião do senso comum.

A despeito disso, o seu entendimento sempre foi buscado, desde os mais remotos tempos, até a atualidade, quer se a trate sob a nomenclatura própria de autonomia, quer se a denomine de liberdade (analisando-se ambas como sinônimas, ou buscando-se alguma possível diferença entre os termos ${ }^{1}$ ).

Com efeito, etimologicamente, conforme se amealha em Rodrigues Junior (2004), a expressão autonomia, presente nos dicionários a partir de 1836, resulta da conjunção de duas palavras gregas, quais sejam: autós e nomói. Da primeira vem a ideia de si mesmo, representando uma qualidade ou condição inerente e peculiar a um ser. A segunda corresponderia à norma ou regra. A junção de ambas gerou autonomia, que ingressou no vernáculo muito provavelmente por influência da palavra francesa autonomie. Já Beauchamp e Childress (2013) explicitam que o vocábulo foi utilizado em primeiro plano para a referência quanto à autogestão ou autogoverno das cidades-estados independentes gregas. Desde então, foi estendido aos indivíduos e ganhou diferentes sentidos, como os direitos de liberdade e privacidade, escolha individual, liberdade da vontade, motor do próprio comportamento, e pertencer a si mesmo.

De seu turno, o ideário de liberdade despontou com os movimentos revolucionários do século XVIII. Neste sentido, Bauman (2014) expõe que a liberdade, assim como a habilidade do autogoverno, antes do "ser deixado só" pelo governo, foi um sonho dos

\footnotetext{
${ }^{1}$ Esclarece-se que a presente pesquisa trabalha com a vertente filosófica segundo a qual liberdade e autonomia não são termos divergentes, mas que se completam mutuamente, sendo a autonomia, nada mais, que a expressão da liberdade.
} 
movimentos de revolução que guiaram o mundo Ocidental na história moderna. Assim, a Revolução Francesa (1789), tinha por intuito transformar o "Terceiro Estado" (a maior parte da população, a quem se negava uma real influência sobre a execução dos assuntos nacionais) em uma força de decisão livre para todas as questões de interesse público. No mesmo sentido, os fundadores da Revolução Americana buscaram em sua Declaração de Independência a garantia de um espaço em que a liberdade pudesse aparecer (liberdade essa entendida como direito pleno e participação universal nos assuntos públicos). Pode-se, então, perceber, que o anseio atrás de uma liberdade que perpassa o direito de não ser incomodado pelos assuntos públicos, sendo, pois, um direito irrestrito e exercido de gerenciá-los, não é novo, tendo acompanhado as sociedades modernas desde o início. A liberdade, inclusive, pode ser concebida como a bandeira levantada pelo liberalismo ${ }^{2}$, como bem supremo do homem, conforme Wolkmer (1995).

Em relação à liberdade de expressão, direito deveras afamado quando se fala em internet, elenca Chequer (2011) que, possui previsão constitucional no Brasil desde a Constituição do Império de 1824. Na Carta Magna de 1988, encontra-se expressamente previsto em inúmeros dispositivos: artigo $5^{\circ}$, incisos IV, IX, XIV e artigo 220, § $1^{\circ}$. Da mesma forma, encontra previsão em documentos internacionais, tais quais: a Declaração Universal dos Direitos do Homem; a Convenção Europeia dos Direitos do Homem; e a Convenção Americana de Direitos Humanos. Ademais, em diversos países ela é consagrada.

Da mesma maneira, a liberdade explanada pode ser vislumbrada enquanto o desimpedimento para a expressão de juízos, críticas e opiniões, acerca de pautas em disputa, além de fatos, ideias e o que mais possa ser visto e demonstrado em público e para o público, no entendimento de Clève e Lorenzetto (2016). Percebe-se, por conseguinte, a sua importância.

Nesta senda, e por fim, realizada esta brevíssima análise acerca dos conceitos atrelados à autonomia: "liberdade" porque expressão da autonomia e "liberdade de expressão" porque termo que demanda análise quando se busca tratar de internet, faz-se oportuna a

\footnotetext{
${ }^{2}$ Segundo Wolkmer (1995), o liberalismo surgiu enquanto nova visão global de mundo, formada por valores, crenças e interesses da burguesia, classe social emergente, na oposição em face da dominação do feudalismo aristocrático fundiário, entre os séculos XVII e XVIII, na Europa. Segundo expõe o autor, essa ideologia converte-se à expressão de uma ética individualista que se volta para a noção de liberdade que se encontra em todos os ângulos da realidade (filosófico, social, econômico, político, religioso, e outros mais).
} 
explicitação do inovador conceito chamado "autonomia decisória", para que, após, munindose de informações suficientes, possa-se analisá-lo conjuntamente com a ideia da internet.

\subsection{A AUTONOMIA DECISÓRIA: O DIREITO À PRIVACIDADE REDIMENSIONADO NA CONSTRUÇÃO DA IDENTIDADE PESSOAL}

A autonomia decisória representa uma inovadora forma de análise em relação ao tema, e consubstancia-se na autonomia que dá armas à construção da identidade pessoal de cada indivíduo, na medida em que possibilita a exteriorização dos anseios pessoais na tomada de importantes decisões de cunho eminentemente pessoal (daí o porquê de também ser conhecida por privacidade decisória), e contribui para o empoderamento da pessoa sobre si própria, sobre seu corpo, e sobre suas decisões. Inclusive, Jean L. Cohen (2012) concebe que tal autonomia envolve o que nomeia como "zona de intimidade". Para ela, ainda, essa é uma área de verdadeiros conflitos e em que é contestado o próprio princípio de um direito individual à privacidade.

Assim, para que se entenda a autonomia decisória, é preciso que se entenda o direito que lhe serve de alicerce, qual seja, o "direito à privacidade pessoal". Este direito possui duas importantes dimensões, conforme Cohen (2012).

A primeira destas dimensões não parece trazer grandes contestações. Consiste no direito de ser "deixado em paz", que é o direito de não sofrer intromissão ou vigilância sem que para isso exista, pelo menos, um justo motivo. No que se relaciona a esta dimensão, Freitas e Pezzella (2013) relatam que não se trata do reconhecimento de mais um direito individual, em termos liberais, mas da proteção da intimidade da pessoa, o que justamente a torna única e a identifica entre todas as demais.

A segunda dimensão, esta sim, mais polêmica, cuida-se da "privacidade decisória", como designam Freitas e Pezzella (2013). É o direito de não ser submetido ao controle indevido, de modo inclusivo no que se relaciona a possíveis regulações por parte de outras pessoas, como pondera Cohen (2012). Pode ser comparada à privacidade vista em Stacy (1991-1992), enquanto direito para a tomada de decisões que alterem (e afetem unicamente) a vida do indivíduo em questão. 
Sendo assim, a primeira dimensão se refere à posse e disseminação de informações, e a segunda, prioritariamente à autonomia decisória relacionada aos aspectos íntimos de cada indivíduo, englobando inclusive a disponibilidade íntima, conforme Cohen (2012).

Esta última dimensão, assim, revela a autonomia decisória a que se almeja considerar. E é em relação a ela que as censuras são tecidas com maior acidez.

Aliás, as críticas relacionadas à autonomia decisória quase sempre levantam a questão concernente ao possível individualismo excessivo, ou a não preocupação com o social, o coletivo, emanada da luta pela preservação dos direitos individuais de liberdade.

Em outras palavras, como revelam Freitas e Pezzella (2013), levando-se em consideração a segunda dimensão apresentada, as principais críticas em relação aos direitos individuais em geral, e de maneira específica em relação aos direitos de privacidade, fazem referência ao modelo liberal sociedade/Estado, que, em suposição, ganharia força pela tutela da privacidade, enquanto "autonomia decisória".

Não parece ser o caso. Aliás, Cohen (2012) sabiamente contrapõe-se às opiniões que acreditam ser as deliberações pautadas na autonomia de decisão como deliberações que levam em conta uma coleção de indivíduos separados, isolados. Relata que o princípio de que os direitos individuais de privacidade, que protegem a autonomia decisória, é compatível com o reconhecimento do caráter intersubjetivo pertencente aos processos de formação da identidade pessoal, e consciência das fontes históricas e contextuais dos valores.

Assim, de acordo com Freitas e Pezzella (2013), o direito à privacidade precisa ser retomado a partir de diferente prisma, especialmente em sua dimensão de autonomia decisória. Conforme as autoras, ele designa o indivíduo como o centro de seu próprio processo de decisão e não determina, por isso, uma escolha ética ou ideológica a ser seguida, senão somente uma esfera de autodeterminação em que cada pessoa pode e deve desempenhar a sua identidade concreta. As escolhas individuais podem ser feitas pelos próprios motivos, como designa Cohen (2012) e, inclusive, não existe a necessidade de que elas sejam justificadas às demais pessoas.

Neste mesmo norte, os direitos de privacidade $^{3}$ pessoal asseguram domínios de autonomia decisória para todos os indivíduos, não gerando uma concepção voluntarista do

\footnotetext{
${ }^{3}$ Jean L. Cohen, no texto "Repensando a privacidade: autonomia, identidade e a controvérsia sobre o aborto", busca definir um novo parâmetro de privacidade, transcendente ao que se conhece, onde justamente a autonomia decisória contribui para a construção da identidade e consequente dignidade pessoal do sujeito.
} 
indivíduo, de modo algum. Sendo assim, quando a questão da autonomia aparece em decisões de Cortes, não há que se impor a elas um ideal voluntarista de pessoa. A atribuição de autonomia decisória a um indivíduo simplesmente milita de forma contrária ao paternalismo estatal.

Freitas e Pezzella (2013) também comentam a crítica recorrente relacionada à percepção de que a autonomia decisória, quando tutela o poder de autodeterminação, estimularia no indivíduo o seu desenraizamento, fazendo, por conseguinte, com que ele rompa com os valores comunitários, quebrando assim os vínculos de solidariedade que o rodeiam.

De fato, para as autoras, a coletividade idealizada enquanto soma de pessoas em que cada qual defende nada mais que seus interesses, traduz-se na negação da possibilidade de existência de um todo social, e se assim fosse, a única identidade possível entre seus membros, conforme explicam, seria a vocação para possuir, que se pretende inerente à "natureza humana".

O que ocorre é que não é esse o caso quando se fala em autonomia decisória, conforme Cohen (2012). Freitas e Pezzella (2013) também deixam isso muito claro. Para as autoras, não parece ser oportuno subordinar o direito à privacidade, especificamente na dimensão decisória, à conotação de indivíduo desenraizado, uma vez que, o que se buscaria verdadeiramente seria a proteção do núcleo de autonomia pessoal, em face das, como definidas por elas, "normas comunitárias" que, em determinadas circunstâncias, poderiam ser abusivas no que toca à autonomia pessoal decisória, e, da mesma forma, em face da própria vontade da maioria, muitas vezes desrespeitosa em relação à diversidade.

Assim, os direitos à privacidade asseguram, de acordo Cohen (2012), a todas as pessoas, precondições para que desenvolvam identidades íntegras que possam avaliar como suas. De outra forma, por garantirem a todos, de maneira igual, personalidade jurídica e autonomia decisória, esses direitos protegem a demanda de cada indivíduo concreto, pouco importando se ele é "diferente" dos demais. Protegem, também, as dimensões pessoais da vida do indivíduo em face da interferência indevida, e resguardam os processos de autodesenvolvimento e autorrealização envolvidos na formação da identidade.

Nada obstante, o exercício da autonomia decisória explanada pressupõe o direito à informação. Explica-se: para que o sujeito possa realizar escolhas embasadas em sua autonomia decisória, ele deve estar muito bem informado acerca dos caminhos a serem percorridos, bem como das consequências da tomada de cada decisão. 
Neste norte é o entendimento de Beauchamp e Childress (2013), que esclarecem que o respeito ao agente autônomo implica o reconhecimento do seu direito de ter opiniões, realizar escolhas e agir embasado nas crenças pessoais. $\mathrm{O}$ respeito explanado envolve uma ação, e exige, do mesmo modo, mais do que obrigações de não intervenção nas decisões, já que inclui obrigações para sustentar as capacidades das pessoas para escolherem autonomamente, diminuindo os medos e demais questões que possam desfavorecer o exercício da autonomia. Isso implica capacitar as pessoas para que ajam autonomamente, informando-as, por conseguinte, e se contrapõe ao desrespeito, que envolve atitudes e ações que ignoram, insultam, ou degradam a autonomia alheia e, por conseguinte, negam a existência de uma mínima igualdade entre as pessoas.

Partindo-se, então, da autonomia sob uma perspectiva positiva de liberdade, não caberia ao Estado interferir nas decisões estritamente pessoais de cada indivíduo, mas caberia, isso sim, informar e disciplinar a sensata utilização da autonomia pessoal, em prol da proteção da privacidade decisória. Dito de outra forma, o Estado não pode exigir que as pessoas revelem as razões para agir em um domínio no qual elas têm o direito de atuar por suas próprias razões, conforme Cohen (2012), mas tem o dever de informação, para que as escolhas sejam feitas com segurança e responsabilidade.

Beauchamp e Childress (2013) esclarecem a necessidade da informação para o desenvolvimento da autonomia de forma específica em relação à ética biomédica, mas vale aqui trazer as suas ponderações, por enriquecerem, e muito, a discussão. Para eles, a autonomia estabelece um direito de autoridade para o controle do próprio destino. Consideram os autores, em uma perspectiva positiva de entendimento do princípio do respeito à autonomia, que existe uma obrigação, também positiva, de tratamento respeitoso na revelação de informações e no consequente encorajamento da decisão autônoma. Assim, muitas ações autônomas demandam a assistência de outras pessoas, para tornarem as opções acessíveis. Especialmente na ética biomédica o respeito à autonomia obriga os profissionais ao esclarecimento das informações, bem como a verificar e assegurar o esclarecimento e a voluntariedade, e ao encorajamento da tomada da decisão adequada segundo os ideais e as crenças de cada pessoa.

Do mesmo modo e em especial porque relevante em assuntos de cunho estritamente pessoal, a autonomia decisória explanada pressupõe o controle de cada pessoa sobre seu próprio corpo, para a salvaguarda da sua dignidade pessoal. Assim, no exercício da autonomia 
decisória, cada indivíduo merece tomar posse do próprio corpo - visualizado este de forma global e integrada -, em face de opiniões da sociedade, da comunidade em que vive, e até mesmo do próprio Estado, na medida em que, se o indivíduo é portador do direito à privacidade decisória, não cabe ao Estado interferir de maneira tão invasiva em sua intimidade, mas garantir condições para o exercício regulamentado da autonomia, atuando, nesse aspecto, de forma positiva.

Freitas e Pezzela (2013), aliás, demonstram a questão da reflexão da autonomia decisória em relação ao direito ao próprio corpo no sentido da reintrodução deste na temática da privacidade. Não, obviamente, na sua dimensão "individualista - possessiva", como se os atributos pessoais, inclusive o próprio corpo, fossem propriedades individuais, ou mercadorias a serem negociadas, mas, como exemplificam, a partir da análise do corpo como um território de si mesmo. No mesmo sentido, Freitas e Zilio (2016) mencionam a existência de uma forte ligação entre o direito de autodeterminação sobre o próprio corpo, e os direitos à privacidade pessoal (em sua dimensão de autonomia decisória), e identidade pessoal. Reiteram que, respeitar a privacidade pessoal de uma pessoa é respeitar o seu direito de se autodeterminar, inclusive corporalmente.

Nessa perspectiva, inclusive, cumpre salientar o sempre adequado pensamento de Goffman (1971). De acordo com o entendimento exarado, o sentimento de controle sobre o próprio corpo é fundamental para uma percepção íntegra de si mesmo, bem como para a própria autoconfiança pessoal. De forma consequente, o controle sobre o corpo é essencial para a configuração da própria identidade, assim como o é para a preservação da dignidade pessoal.

Sendo assim, percebe-se cristalinamente que, a autonomia decisória pleiteada, emanada enquanto pilar do direito à privacidade, busca redimensionar a dignidade, construindo assim, a dignidade pessoal, por intermédio da descoberta da identidade pessoal, e, pressupõe, à vista disto, o controle do indivíduo sobre si, em termos globais.

Ademais, percebe-se que tal autonomia parte do ideal de indivíduo que toma as suas decisões de maneira consciente, porém, age não enquanto ser desenraizado do social, mas enquanto agente socializado que busca, a despeito disso, o atendimento de seus interesses em decisões de cunho pessoal. A partir do momento que segue, outrossim, o estudo busca realizar uma análise dessa socialização, questionando a relação da internet com o isolamento social, e a possível construção de uma pseudoautonomia. 


\section{A INTERNET E O ISOLAMENTO SOCIAL ${ }^{4}$ : UMA "PSEUDOAUTONOMIA"?}

Em um primeiro momento, é preciso que se relacione, como já delineado por Lévy (1996) que o virtual (aqui trazido especificamente no seu sentido informático), pode, de fato, ter certa afinidade com o falso, com o ilusório e com o imaginário. Não obstante, essa afinidade é deveras pequena, de modo que o virtual se trata, em detrimento disso, de um modo de ser bastante fecundo, que põe em jogo processos de criação, que constrói futuros, e que abre nichos de sentido sob a platitude da presença física imediata ${ }^{5}$.

Dito isto, imprescindível elencar-se que a opinião de que a internet em nada facilita a chamada socialização dos indivíduos, levando, isso sim, a um verdadeiro isolamento social, é extremamente recorrente, e merece a consideração do estudo. Aliás, como pondera Lemos (2010), há certa tendência, nos indivíduos, a vislumbrar os efeitos "nefastos", por assim elencar, das tecnologias, em relação à cultura, à política, e, ademais, à vida social.

Sendo deste modo, sob o ponto de vista elencado, a internet de modo algum promoveria o processo de emancipação dos indivíduos, mas geraria, de fato, o que nesse estudo se denomina de uma "pseudoautonomia": o indivíduo agiria unicamente como "massa de manobra", crendo com veemência ser, de fato, autônomo.

Realmente, reconhecer-se autônomo em tempos de uma, como denominada por Bauman (2009), "sociedade líquido-moderna", em que as condições pelas quais agem os seus membros mudam em um intervalo de tempo mais curto do que o necessário para a consolidação das formas de agir, parece ser um constante desafio.

Por certo, nada é pacífico em relação à interação propiciada pela internet e as suas consequências. Sobre o tema, a psicóloga Dora Sampaio Góes, do Grupo de Dependência de Internet do Instituto de Psiquiatria do Hospital das Clínicas da Universidade de São Paulo

\footnotetext{
${ }^{4}$ Outra dura crítica relacionada ao surgimento da internet refere-se à exclusão. Lévy (2000) relaciona a exclusão como uma das implicações sociais do que denomina ciberespaço, mencionando que, o paradoxo dos sistemas de informação de comunicação universal reside em que eles, por via de consequência, podem trazer, em princípio, certa exclusão. Porém, para o autor, isso não é razão para que as pessoas se posicionem de forma contrária à utilização da internet. Pierre Lévy menciona, ao que parece tecendo verdadeira crítica, que, aqueles que trazem à tona, na maioria das vezes, a ideia da exclusão e da desigualdade, não são os desfavorecidos de fato, mas aqueles que correm o risco de perder uma parcela de seu poder.

${ }^{5}$ Lévy (1996) tece críticas às afirmações de que a virtualidade e a realidade são esferas distintas, contrapostas. Do mesmo modo, Lévy (1999) questiona, e critica, metaforicamente, a questão do impacto trazido pela tecnologia. No ponto de vista do autor, a interpretação de que a tecnologia poderia ser comparada a um verdadeiro projétil, e a sociedade, ou a cultura, a um verdadeiro alvo vivo, está inadequada.
} 
(USP), em entrevista ao Globo Ciência, em 2013, pondera que, sim, o uso demasiado das tecnologias pode trazer riscos à vida social, na medida em que "desconecta" as pessoas do mundo real. Para chegar ao resultado citado, a profissional menciona que não somente o tempo gasto com os aparelhos eletrônicos deve ser levado em consideração, mas também a forma como eles são utilizados, e os contextos ${ }^{6}$.

Segundo o que se aufere da opinião exarada, os casos de isolamento social, possivelmente ocasionados pelo uso da internet, passam pelo comportamento compulsivo do indivíduo, que se torna um verdadeiro "viciado".

Entretanto, saber até que ponto as informações recebidas via internet podem influenciar os sujeitos, desprovendo-os de opinião própria em relação a determinados assuntos, é um ponto crucial na discussão.

É consabido que não somente a internet, mas todos os meios de comunicação em massa podem exercer, e, de fato, exercem, influência sobre os indivíduos. A autoridade midiática exercida em relação à população chega a ser absurda, mas é justamente aí que, no contraponto da questão, busca-se posicionar a internet como forma de desenvolver-se a autonomia decisória dos sujeitos: primeiro porque a autonomia que se defende aqui pressupõe o direito à informação, na medida em que pessoas bem informadas não agem enquanto "massa de manobra", mas concretizam suas escolhas éticas de acordo com seus valores, construídos ao longo da vida, e a internet pode facilitar, e muito, o acesso à informação; e segundo, porque a autonomia aqui ponderada não parte de ideais de pessoas deslocadas, desenraizadas do todo social, mas de pessoas socializadas, porém que, a despeito disso, conseguem fazer suas escolhas em detrimento das "normas comunitárias", que podem ser, e muitas vezes são, abusivas no que toca a escolhas de cunho particular e pessoal, situadas na "zona de intimidade".

Considera-se, assim, que o indivíduo socializado virtualmente, pode sim fortalecer os vínculos sociais emanados da "vida real", desde que os instrumentos tecnológicos postos à sua disposição sejam usados com parcimônia. Ademais, porque provido de informações e desde que socializado, o mesmo indivíduo pode ter na internet um meio de promoção da sua autonomia. É, aliás, o que se buscará ponderar a partir de agora.

\footnotetext{
${ }^{6}$ A profissional expõe que a tecnologia pode prender a atenção das pessoas de maneira significativa, ao ponto de, inclusive, elas se desconectarem do que ocorre à sua volta. Isso também deve ser levado em consideração, e não somente o fator tempo.
} 


\section{A INTERNET COMO MEIO DE FOMENTO À AUTONOMIA DECISÓRIA E COMO FORMA DE SOCIALIZAÇÃO}

Em que pese seja evidente a importância do alhures explicitado em relação ao isolamento social, as opiniões que consideram a internet como nova forma de interação social, e, consequentemente, de socialização e de meio de construção da autonomia alicerçada no direito à informação, são cada vez mais concretas e plausíveis.

Quanto à relação entre a autonomia das pessoas e a internet, a concepção do sociólogo Manuel Castells faz-se oportuna. Segundo Castells (2003), por um lado, ao permitir acessar toda a informação, a internet pode aumentar a incerteza, mas, de outro turno e ao mesmo tempo, é um instrumento chave para a autonomia das pessoas. Quanto mais autônomo é um indivíduo, mais ele utiliza a internet. $\mathrm{O}$ autor relata que quando uma pessoa tem um forte projeto de autonomia, em qualquer dimensão, ela utiliza a internet com muito mais frequência e intensidade. E o uso da internet reforça, por sua vez, a autonomia desta pessoa. Com efeito, pondera o autor que quanto mais uma pessoa controla a sua vida, menos ela se fia nas instituições.

É claro e evidente, conforme delineado oportunamente, que a expressão da autonomia decisória demanda o direito à informação. $\mathrm{O}$ indivíduo deve, assim, exercer a sua autonomia de decisão desde que verdadeiramente munido das informações que lhe são cabíveis, para que, de fato, não expresse o que se denominou de uma "pseudoautonomia", servindo, ademais, de "massa de manobra", ao considerar-se autônomo, quando, ao invés disso, somente repete o que é conveniente para a "elite", ou, talvez, para a "maioria".

Evidentemente, o exagero na oferta de informações ${ }^{7}$ via internet pode levar as pessoas à inércia, uma vez que, tudo o que é excessivo pode acarretar a sensação de confusão. Cabe, então, realizar-se uma filtragem do que é trazido para que a construção da autonomia e o empoderamento das decisões de fato ocorram.

Como corolário, considera-se, ademais, que a liberdade de expressão pode ser concretizada e instrumentalizada por meio da internet. Sobre tal liberdade, mencionam Versuti, Cunha e Cruz e Costa (2015) que, um dos elementos incentivadores da expansão da

\footnotetext{
${ }^{7}$ Cebrián (1999), nesta mesma senda, questiona-se se a abundância de informações melhora o nível de vida. Para o autor, por vezes pode significar confusão. O excesso de dados, prioritariamente quando chega às pessoas de maneira desordenada e aleatória, pode conduzir a uma situação confusa, e trazer uma verdadeira e poderosa sensação de incerteza.
} 
civilização foi a liberdade de se expressar, de externar a reflexão interna. Neste liame, o pensamento reflexivo por si só, dissociado de interferências externas, é meio de expressão das outras liberdades, já que a liberdade para se expressar seria a base de todas as demais liberdades humanas. Como "ser" de discurso articulado que é, o ser humano consegue transcender as barreiras da individualidade e expressar-se livremente.

Com efeito, de acordo com o que colocam, com a comunicação e a interação, os indivíduos são capazes de armazenar aquilo que já adquiriram, e se desenvolver como elementos integrantes da natureza, convertendo-se à condição de seres inteligíveis, já que o pensamento requer conhecimento, e o conhecimento caminha lado a lado com a liberdade. Os autores relacionam que o ser humano notou que não apenas existe ou vive, mas coexiste e convive, de modo que necessita dos demais indivíduos para se identificar, construir e desenvolver.

A passagem do isolamento para o relacionamento, aliás, começa por meio dos primeiros meios de comunicação, de modo que o fluxo dos pensamentos e ideias é tão imprescindível para vida em sociedade, quanto o é a própria liberdade física, conforme Versuti, Cunha e Cruz e Costa (2015). Ao que parece, a questão relativa ao relacionamento pode ser verificada, primordialmente na atualidade, com a expansão da internet, - que intensifica, e muito, esse processo.

Inclusive, como asseguram Clève e Lorenzetto (2016), na atualidade, a premissa inicial que orienta a liberdade de expressão é a de que não há que se falar em interferência estatal nos conteúdos apresentados pelos diversos meios de comunicação. Isso faz com que prevaleça, em princípio, além da ideia de não interferência estatal, a maximização da liberdade informativa.

Outrossim, é perceptível, a olhos vistos, o quanto as noções de autonomia e, consequentemente, de liberdade, e de liberdade de expressão, sob este ponto de vista, podem se ligar à noção da ideia da internet, e ao desenvolvimento da, como denominada pelo sociólogo Manuel Castells, "sociedade em rede", o que é verdadeiramente fascinante e facilitador do desenvolvimento das potencialidades humanas.

\footnotetext{
${ }^{8}$ Sobre a sociedade em rede, Castells (2002a) especifica que há uma tendência histórica de que as funções e os processos dominantes na era da informação sejam cada vez mais organizados em tornos das redes. Estas formam a nova morfologia social das hodiernas sociedades e a sua difusão lógica modifica de maneira substancial a operação e os resultados dos processos de produção, e de experiência, poder e cultura. A forma de organização social em redes, segundo explana, existiu em outros tempos e espaços, mas o inovador paradigma da tecnologia da informação propicia a base material para a sua expansão penetrante em toda a estrutura social.
} 
Neste liame, Castells (2003) relata que, a emergência da internet enquanto novo modo de comunicação esteve ligada a afirmações conflitantes acerca de novos padrões de interação social. Em um vértice, a formação de comunidades virtuais, pautadas em comunicação online, foi interpretada como a culminação de um processo histórico de desvinculação entre localidade e sociabilidade na formação da comunidade, ou seja, novos padrões de relações sociais substituem as formas de interação humana territorialmente limitadas. Claro que os padrões sociais são distintos daqueles de outrora. Aliás, conforme já explanado por Thompson (2011), o desenvolvimento da própria mídia modificou a constituição espacial e temporal da vida social, ensejando formas novas de agir e de interagir, que se desvinculam do padrão de estar-se em um lugar comum ${ }^{9}$.

Então, quanto à sustentação de que a difusão da internet leva a certo isolamento social, à medida que indivíduos sem face praticam uma sociabilidade aleatória, abandonando interações em ambientes reais, pondera Castells (2003) que, nos tempos hodiernos, as limitações vêm desaparecendo, e as pessoas deveriam ser capazes de avaliar os padrões de sociabilidade oriundos do uso da internet, ao menos em sociedades desenvolvidas, onde existe grandiosa difusão. Há disponibilidade suficiente de dados e análises para a formulação de interpretações mais seguras do que as interpretações populares. Contudo, ao que parece, o debate público ainda é dominado por dicotomias simplistas, ideológicas, que tornam mais dificultosa a compreensão dos novos padrões de interação social.

Sobre a versão de que a internet, primordialmente através das tão difundidas redes sociais, possibilita a existência de um local para além de virtual, irreal, onde são construídas realidades paralelas, expõe Castells (2003) que a "representação de papéis" e a construção de outra identidade ${ }^{10}$ como suporte da interação online, representam uma parcela quase

\footnotetext{
${ }^{9}$ Thompson (2011) argumenta que o desenvolvimento dos meios de comunicação, para além de criar novos jeitos de interação, fez surgir novos meios de ação, que possuem caracteres e consequências bem distintas. Explica que a característica mais geral é que eles são responsivos e orientados a ações ou pessoas que estão situadas em contextos espaciais remotos (e, quiçá, em contextos temporais remotos), ou seja, o desenvolvimento dos meios de comunicação levou ao surgimento de novas maneiras de ação à distância, que, na modernidade, tornaram-se cada vez mais comuns. Se nas mais antigas sociedades as ações e as consequências ficavam restritas aos contextos de interação face a face, atualmente, não raro verem-se as pessoas orientarem suas ações para outros que não partilham o mesmo ambiente "espaçotemporal", e com consequências que extrapolam os limites de seus contextos e localizações.

${ }^{10}$ Castells (2002b) entende a identidade enquanto fonte de significado e experiência de determinado povo. Em relação aos atores sociais, ela é o processo de construção de significado baseada em um atributo cultural, ou um conjunto deles inter-relacionados, que prevalecem sobre outras fontes de significado. Complementa o autor que para um indivíduo, ou para a coletividade, podem existir identidades múltiplas, e essa pluralidade pode gerar tensão e contradição tanto na autorrepresentação quanto na ação social. Isso, pois se faz necessário distinguir a
} 
insignificante da sociabilidade baseada na internet. Ainda, esse tipo de prática parece estar concentrada entre os adolescentes. Inclusive, houve uma distorção, para o autor, da percepção pública da prática social da internet, mostrando-a como espaço privilegiado para fantasias pessoais. Na maioria das vezes, ela não retrata isso, mas sim a extensão da vida real, em todas as dimensões e sob todas as modalidades.

Repare-se que, aqueles que vivem vidas paralelas na tela são pessoas limitadas por desejos, dor e mortalidade das pessoas físicas que estão por trás. Para Castells (2003), a representação de papéis é uma experiência social válida, porém, de forma alguma constitui uma proporção significativa da interação social da internet, atualmente. Aliás, o autor cita que os usuários da internet tendem mais do que os não usuários a encontrar os amigos e ter uma vida social longe de casa. Para ele, se algo pode ser dito, é que a internet parece ter efeito positivo sobre a interação social, assim como tende a aumentar a exposição a diferentes maneiras de informação (o que pode facilitar a expressão da autonomia decisória).

O que pode levar a um isolamento (supostamente causado pela internet), para o autor, é a inexperiência no uso da internet, e não o seu uso propriamente dito. Para tal constatação baseia-se em estudos científicos sérios. Inclusive, o sociólogo relaciona que existe uma constante interação entre o espaço físico e a internet.

Logo, Castells (2003) toma posicionamento contrário à tese de que o uso da internet acarreta menor interação e maior isolamento social. O que existem, para ele, são indícios de que em certas circunstâncias, o seu uso pode servir de substituto para algumas atividades sociais.

Na mesma linha de raciocínio, Castells (2003) propõe que o passo analítico necessário para a compreensão das novas formas de interação social na era da internet seja ter em mente uma redefinição de comunidade, em que seja dado menor ênfase a seu componente cultural, e maior ênfase a seu papel de apoio a indivíduos e famílias, desvinculando sua existência social de um tipo único de suporte material. O ponto decisivo é o deslocamento da comunidade para a rede como a maneira central de organizar a interação. Pelo menos na tradição da pesquisa sociológica, as comunidades pautavam-se no compartilhamento de valores e organização social. As redes, ainda, são organizadas pelas escolhas e estratégias dos

"identidade" do que os sociólogos comumente chamam de papéis: papéis são definidos por normas estabelecidas pelas instituições e organizações sociais; identidades, de seu turno, são fontes de significado para os próprios atores, por eles originadas e estabelecidas através de um processo de individuação (as identidades assumem tal condição desde que os atores sociais as internalizem, construindo seu significado alicerçados nessa internalização). 
atores sociais, quer sejam indivíduos, famílias ou grupos sociais. Assim, a grande transformação da sociabilidade em sociedades complexas deu-se com a substituição de comunidades espaciais por redes como formas fundamentais de sociabilidade. Isso em relação a amizades, e, prioritariamente, em relação aos laços de parentesco, pois a família extensa encolheu e os novos meios de comunicação possibilitaram a manutenção do contato à distância com os familiares.

Ainda, para o autor, o individualismo em rede é um padrão social, e não, como pode parecer, um acúmulo de pessoas isoladas. Os indivíduos montam suas redes online e offline com base em seus interesses, em seus projetos, em seus valores e em suas afinidades. Tendo em vista a flexibilidade e o poder de comunicação da internet, a interação social online desempenha papel em crescimento na organização social como um todo, e as redes online podem formar comunidades virtuais, que são diferentes das físicas, mas não menos intensas ou menos eficazes na criação de laços e na mobilização. Ademais, o que o que se pode observar nas sociedades é o desenvolvimento de uma comunicação híbrida (lugar físico e ciberlugar), para operar como apoio material do individualismo em rede. Assim, a internet traz uma diferenciada maneira de organização comunitária, estabelecida por meio das comunidades virtuais ${ }^{11}$, que proporcionam a sociabilidade em um novo modelo, estabelecido através do individualismo em rede.

Tal conceito liga-se à questão da autonomia decisória do indivíduo, não enquanto autonomia de não intervenção, nos moldes liberais, tampouco emanada de ideais comunitaristas, mas enquanto verdadeiramente uma nova forma de abordagem do tema, onde o indivíduo é socializado, sociável, pertencente à comunidade em que se encontra, mas que exerce sua autonomia, uma vez que tem poder de decisão e tem o direito de expressar-se e levar a sua vida de acordo com o que considera digno para si, a despeito dos valores adotados pelo todo.

Veja-se a pertinência da colocação da internet nesse rumo, ou seja, essa ferramenta importantíssima serve de instrumento para a expressão do ser humano enquanto ser sociável, mas autônomo. Outrossim, a internet a que se pretende aqui demonstrar, é aquela que permite a sociabilidade, mas sem que se perca a noção do indivíduo (o próprio individualismo em rede, que não prega que as pessoas sejam ou estejam isoladas, mas que possuam individualidades), de indivíduo que se autodetermina.

\footnotetext{
${ }^{11}$ Perceba-se a disseminação das denominadas redes sociais.
} 
Ademais, o direito à informação é pressuposto para o desenvolvimento da verdadeira autonomia decisória, e, indubitavelmente, a internet pode servir de instrumento facilitador do acesso à informação, auxiliando, assim, na construção do poder de decisão, desde que filtrado o excesso ofertado.

Por fim, é evidente que a "explosão" da internet trouxe consigo questões polêmicas, e, em que pese seja um acontecimento relativamente recente, as consequências do seu advento já permeiam discussões há tempos. Por certo ainda não é extremamente claro se as novas formas de interação social promovidas trazem mais malefícios do que benefícios, mas, o que parece certo é que houve uma quebra de paradigmas, e as consequências dessa quebra ainda precisarão ser estudadas ao longo dos anos.

\section{CONSIDERAÇÕES FINAIS}

$\mathrm{Na}$ atualidade, ainda mais do que outrora, a internet tem tomado espaço cada vez mais considerável na vida das pessoas. Em que pese boa parte da população ainda não tenha acesso a tal ferramenta (principalmente em termos de Brasil), de modo geral ela representa um papel significativo na vida dos indivíduos - seus usuários.

É certo que há, ainda, muito a se refletir acerca das questões emanadas do advento da internet, e foi justamente tal motivo que ensejou a construção do presente estudo.

Neste norte, a preocupação aqui se coadunou em questionar se a internet pode facilitar a socialização, através de uma nova forma de interação social, e, igualmente, promover a autonomia decisória dos indivíduos.

A sociabilidade a que se almejou considerar parte do ideal de pessoas que respeitam as suas próprias individualidades, e as individualidades alheias, mas que, apesar disso, participam da ideia de sociedade e não de isolamento. A partir daí é que se ponderou a ideia de autonomia, com base na percepção da existência de indivíduos socializáveis, mas que respeitam as suas peculiaridades e anseios pessoais, e que, munidos das informações pertinentes, agem de acordo com os próprios valores em decisões envoltas por sua "zona de intimidade".

É verdade que o uso da internet, em específicas circunstâncias, pode trazer riscos ao desenvolvimento da socialização das pessoas, - ainda mais quando a utilização ocorre de maneira descontrolada e quiçá, compulsiva. É inegável que se considere que tal efeito pode 
sim ser causado, mas parece ser o caso de ponderar-se como, em que medida, e com qual finalidade a internet é utilizada. Também, não se pretende aqui levantar a hipótese de que em nenhuma circunstância essa ferramenta pode influenciar os indivíduos, mas trazer à baila que não somente efeitos negativos advêm do seu uso, mas, de outro lado, efeitos positivos que, com efeito, deve-se ter em conta.

O que se pode considerar com a abordagem feita, logo, é que a internet, em oposição ao que em regra se pensa, pode sim servir como forma de socialização, e não de isolamento, na medida em que, em geral, as pessoas, utilizando-se das ferramentas da internet, tornam-se mais receptíveis a novos padrões de sociabilidade, e não necessariamente ficam somente em frente às telas de computadores isoladas do mundo real. Ou seja, a internet serve como meio facilitador das relações interpessoais que ocorrem na "vida real", refletindo o que elas são na realidade. Ocorre, com isso, um diferenciado padrão de interação social. Daí, talvez, toda a polêmica levantada.

Ao mesmo tempo, a internet, por meio do fornecimento de informações, pode favorecer a expressão da autonomia dos indivíduos. O indivíduo legitimamente autônomo utiliza-se desse meio (internet) como suporte para o seu desenvolvimento pessoal, e não como meio de influência em suas decisões.

Importante lembrar que a autonomia e a consequente liberdade de expressão podem e devem alcançar limites, inclusive no mundo digital, uma vez que em absoluto a internet é o que se pode denominar de uma "terra de ninguém", onde se fala e se faz o que se quer sem haver sanções. Exemplo disso pode ser concretizado averiguando o Marco Civil da Internet (Lei $\mathrm{n}^{\circ}$ 12.965, de 23 de abril de 2014) e a Lei Geral de Proteção de Dados Pessoais (Lei ${ }^{\circ}$ 13.709, de 14 de agosto de 2018).

Com efeito, pode-se ressaltar que o mundo da internet não necessariamente é alheio ao mundo real, e como bem ponderado ao longo do texto, a vida expressa na internet, na maioria das vezes, é reflexo da própria vida real, tanto na questão da sociabilidade quanto na questão da expressão da autonomia, até porque, ambas as questões se tornam complementares (perceba-se o indivíduo enquanto ser socializado, mas portador de individualidade e poder de autodeterminação/autonomia).

Portanto, de acordo com esse entendimento, a internet pode alicerçar o indivíduo enquanto ser sociável, porém autônomo. Igualmente, pode permitir a sociabilidade, mas 
coadunada à noção de individualidade, de indivíduo que justamente se autodetermina e busca a realização dos seus intentos, empoderando-se de suas decisões.

\section{REFERÊNCIAS}

BAUMAN, Zygmunt. Liberdade. Tradução Silvana Perrella Brito. 1 ed. Santo André: Academia Cristã, 2014. 148 p. Tradução de: Freedom.

Vida Líquida. Tradução Carlos Alberto Medeiros. 2. ed. rev. Rio de Janeiro: Jorge Zahar, 2009. 210 p. Tradução de Liquid life.

BEAUCHAMP, Tom L.; CHILDRESS, James F. Princípios de ética biomédica. Tradução Luciana Pudenzi. 3. ed. São Paulo: Loyola, 2013. 574 p. Tradução de: Principles of Biomedical Ethics.

CASTELLS, Manuel. A galáxia da Internet: reflexões sobre a internet, os negócios e a sociedade. Tradução Maria Luiza X. de A. Borges. Revisão Técnica Paulo Vaz. Rio de Janeiro: Jorge Zahar, 2003. 243 p. Tradução de: The internet galaxy: reflections on the internet, business and society.

. A Era da Informação: economia, sociedade e cultura - a sociedade em rede. vol. I. Tradução Roneide Venancio Majer. 6. ed. rev. e ampl. São Paulo: Paz e Terra, 2002a. 698 p. Tradução de: The rise of the network society.

A Era da Informação: economia, sociedade e cultura - o poder da identidade. vol II. Tradução Klauss Brandini Gerhardt. 3. ed. São Paulo: Paz e Terra, 2002b. 530 p. Tradução de The power of identity.

CEBRIÁN, Juan Luis. A rede: como nossas vidas serão transformadas pelos novos meios de comunicação. Tradução Lauro Machado Coelho. São Paulo: Summus, 1999. Tradução de La red.

CHEQUER, Cláudio. A liberdade de expressão como direito fundamental preferencial prima facie: (análise crítica e proposta de revisão do padrão jurisprudencial brasileiro). Rio de Janeiro: Lumen Juris, 2011.

CLÈVE, Clèmerson Merlin; LORENZETTO, Bruno Meneses. Dimensões das liberdades de informação e de expressão: elementos do discurso público. Revista Espaço Jurídico Journal of Law, Joaçaba, v. 17, n. 1, p. 83-98, 2016. Disponível em:<http://editora.unoesc.edu.br/index.php/espacojuridico/article/view/9296/pdf > . Acesso em: 21 jul. 2021.

COHEN, Jean L. Repensando a privacidade: autonomia, identidade e a controvérsia sobre o aborto. Revista Brasileira de Ciência Política. Brasília, DF, n. 7, p.165-203, abr. 2012.

FREITAS, Riva Sobrado de; PEZZELLA, Maria Cristina Cereser. As dificuldades da constitucionalização do direito ao corpo: liberdade de expressão e discriminação social. 
Revista Brasileira de Direitos Fundamentais e Justiça, Porto Alegre, ano 7, n. 24, p. 175195, 2013. Disponível em:

<http://www.dfj.inf.br/Arquivos/PDF_Livre/24_Doutrina_Nacional7_OK.pdf >. Acesso em: 26 out. 2020.

; ZILIO, Daniela. Os direitos da personalidade na busca pela dignidade de viver e de morrer: o direito à morte (digna) como corolário do direito à vida (digna). Revista de Direitos e Garantias Fundamentais, Vitória, v. 17, n. 1, p. 171-190, 2016. Disponível em: <http://www.fdv.br/sisbib/index.php/direitosegarantias/article/view/733/281>. Acesso em: 23 maio 2021.

GÓES, Dora Sampaio. Uso excessivo das tecnologias pode trazer sérios riscos à vida social. São Paulo, 31 ago. 2013. Entrevista concedida ao Globo Ciência. Disponível em: $<$ http://redeglobo.globo.com/globociencia/noticia/2013/08/uso-excessivo-das-tecnologiaspode-trazer-serios-riscos-vida-social.html>. Acesso em: 4 jul. 2021.

GOFFMAN, Erving. Territories of the self. Relations in public. Nova Iorque: Harper, 1971.

LEMOS, André. Cibercultura: tecnologia e vida social na cultura contemporânea. 5. ed. Porto Alegre: Sulina, 2010. 295 p.

LÉVY, Pierre. A Revolução contemporânea em matéria de comunicação. In: MARTINS, Francisco Menezes; SILVA, Juremir Machado da (Org.). Para navegar no século XXI: Tecnologias do imaginário e cibercultura. 2. ed. Porto Alegre: Sulina/Edipucrs, 2000. p. 195223.

Cibercultura. Tradução Carlos Irineu da Costa. 1.ed. São Paulo: Editora 34, 1999. 264 p. Tradução de: Cyberculture.

O que é virtual? Tradução Paulo Neves. Revisão Técnica Carlos Irineu da Costa. 1. ed. São Paulo: Editora 34, 1996. 160 p. Tradução de: Qu'est-ce que le virtuel?

RODRIGUES JUNIOR, Otávio Luiz. Autonomia da vontade, autonomia privada e autodeterminação: notas sobre a evolução de um conceito na modernidade e na pósmodernidade. Revista de Informação Legislativa, Brasília, v. 41, n. 163, p. 113-130, 2004. Disponível em:<http://www2.senado.leg.br/bdsf/item/id/982 >. Acesso em: 21 set. 2020.

STACY, Tom. Death Privacy and the Free Exercise of Religion. Cornell Law Review 77.3 (1991-1992): 490-595. Disponível

em: <http://heinonline.org/HOL/Page?handle=hein.journals/clqv77\&div=22\&start_page=490 \&collection=journals\&set_as_cursor=0\&men_tab=srchresults $>$. Acesso em: 21 jul. 2021.

THOMPSON, John B. A mídia e a modernidade: uma teoria social da mídia. Tradução Wagner de Oliveira Brandão. Revisão da Tradução Leonardo Avritzer. 12. ed. Petrópolis: Vozes, 2011. 359 p. Tradução de: The media and modernity: a social theory of the media.

VERSUTI, Andrea Cristina; CUNHA E CRUZ, Marco Aurélio Rodrigues da; COSTA, Carlos. Contribuições ao debate sobre autonomia e liberdade de expressão em tempos de convergência e educação aberta. Revista Iberoamericana de Filosofía, Política y 
Humanidades, Sevilla, v. 17, n. 33, p. 125-150, 2015. Disponível em:

<http://www.redalyc.org/articulo.oa?id=28238686006>. Acesso em: 10 abr. 2021.

WOLKMER, Antonio Carlos. Ideologia, Estado e Direito. 2. ed. rev. e ampl. São Paulo:

Revista dos Tribunais, 1995. 207 p. 